\title{
Seismic observations of a complex firn structure across the Amery Ice Shelf, East Antarctica
}

\section{Article \\ ${ }^{*}$ Present address: IMAS - Hobart, Private Bag 129, Hobart, TAS 7001, Australia. \\ Cite this article: Hollmann $\mathrm{H}$, Treverrow $\mathrm{A}$, Peters LE, Reading AM, Kulessa B (2021). Seismic observations of a complex firn structure across the Amery Ice Shelf, East Antarctica. Journal of Glaciology 67(265), 777-787. https://doi.org/10.1017/jog.2021.21}

Received: 4 October 2019

Revised: 4 February 2021

Accepted: 5 February 2021

First published online: 2 March 2021

Keywords:

Polar firn; seismics; snow mechanics

Author for correspondence:

Hannes Hollmann,

E-mail: hannes.hollmann@utas.edu.au
Hannes Hollmann ${ }^{1, \star} \mathbb{D}$, Adam Treverrow ${ }^{1}$, Leo E. Peters ${ }^{2}$, Anya M. Reading ${ }^{3}$ and Bernd Kulessa ${ }^{4}$

${ }^{1}$ Institute for Marine and Antarctic Studies, University of Tasmania, Hobart, Tasmania, Australia;; ${ }^{2}$ Seismic Research Centre, University of the West Indies, St Augustine, Trinidad and Tobago;; ${ }^{3}$ School of Natural Sciences (Physics), University of Tasmania, Hobart, Tasmania, Australia and ${ }^{4}$ College of Science, Swansea University, Swansea, UK

\begin{abstract}
We use seismic refraction data to investigate the firn structure across a suture zone on the Amery Ice Shelf, East Antarctica, and the possible role of glacier dynamics in firn evolution. In the downstream direction, the data reveal decreasing compressional-wave velocities and increasing penetration depth of the propagating wave in the firn layer, consistent with $\sim 1 \mathrm{~m}$ firn thickening every $6 \mathrm{~km}$. The boundary between the Lambert Glacier unit to the west and a major suture zone and the Mawson Escarpment Ice Stream unit to the east, is marked by differences in firn thicknesses, compressional-wave velocities and seismic anisotropy in the across-flow direction. The latter does not contradict the presence of a single-maximum crystal orientation fabric oriented $45-90^{\circ}$ away from the flow direction. This is consistent with the presence of transverse simple shear governing the region's underlying ice flow regime, in association with elevated strain along the suture zone. The confirmation and quantification of the implied dynamic coupling between firn and the underlying ice requires integration of future seismic refraction, coring and modelling studies. Because firn is estimated to cover $\sim 98 \%$ of the Antarctic continent any such coupling may have widespread relevance to ice-sheet evolution and flow.
\end{abstract}

\section{Introduction}

Firn is a porous, intermediate layer of polar ice sheets that exists between freshly accumulated snow and the underlying glacial ice (Cuffey and Paterson, 2010, Ch. 2). Currently, modelling firn densification is a major source of uncertainty in ice-sheet mass-balance estimates using altimetry measurements - where the thickness change associated with densification can be greater than that due to changes in the accumulation rate (e.g. Helsen and others, 2008; Shepherd and others, 2012). For ice core climatological records, firn models are essential to determine the age difference between the ice matrix and the age of gases trapped within (e.g. Parrenin and others, 2012). In both cases the accuracy of model estimates is limited by our understanding of firn densification and structural evolution.

The firn layer covers $>98 \%$ of the Antarctic continent (Winther and others, 2001; Burton-Johnson and others, 2016) and it is characterised by an increasing density with depth. The thickness of the firn is determined by the depth at which density approaches that of polycrystalline ice, i.e. $830 \mathrm{~kg} \mathrm{~m}^{-3}$ when the pore close-off depth is reached. The process of firn densification is primarily driven by the mean annual surface temperature and accumulation rate (e.g. Herron and Langway, 1980; Alley, 1987a; Kameda and others, 1994), accompanied by wind (Craven and Allison, 1998) and the magnitude of deviatoric stresses in the region (Riverman and others, 2019). Firn densification is a complex process that can be considered to occur in four stages. The first spans from freshly accumulated snow to a density of $\sim 550 \mathrm{~kg} \mathrm{~m}^{-3}$ - which corresponds to a porosity of $40 \%$ - and is primarily driven by the settling and rounding of ice crystals (e.g. Alley, 1987a); however, recent tomographic analyses suggest that this boundary is not as clearly defined as previously thought (Freitag and others, 2008). A second stage of densification to $\sim 730 \mathrm{~kg} \mathrm{~m}^{-3}$ occurs through an increase in the surface contact area between adjacent particles via sublimation, diffusion (e.g. Hobbs and Mason, 1964; Ebinuma and others, 1987), and later recrystallisation (Alley and Bentley, 1988). Viscoplastic deformation due to increasing overburden pressure drives the third densification stage until pore close-off is reached at $\sim 830 \mathrm{~kg} \mathrm{~m}^{-3}$ (Maeno and Ebinuma, 1983), i.e. when air entrapped in the firn forms discrete bubbles within the polycrystalline ice matrix. A fourth stage of slow density increase, up to $\sim 917 \mathrm{~kg} \mathrm{~m}^{-3}$, is associated with compression of these air bubbles (Lipenkov and others, 1997).

Seismic techniques can image the physical properties of the firn and thereby expand the centimetre-scale limitations imposed by firn core studies. In firn and ice, differences in density lead to differences in the propagation velocity of seismic waves (Kohnen, 1972). The continuous densification of the firn layer with depth enables the seismic velocity structure to be determined in detail by applying a diving-wave inversion of the first arrival travel times (Slichter, 1932; Kirchner and Bentley, 1990; Diez and others, 2013). This allows analyses of physical 
properties of the firn, e.g. thickness, elastic moduli, Poisson's ratio, density and temperature (Kohnen, 1972, 1974; King and Jarvis, 2007). The directional dependence of the seismic velocity, i.e. the seismic anisotropy of the firn, can also be determined by acquiring seismic data in different horizontal directions (Kirchner and Bentley, 1979, 1990; Schlegel and others, 2019).

The mechanical properties of the firn are commonly assumed to be vertically anisotropic (directionally dependent) and transversely isotropic (directionally independent) (e.g. Alley, 1980, 1987b; Luciano and Albert, 2002; Fujita and others, 2009; Lomonaco and others, 2011). Firn anisotropy is often attributed to structural processes during densification where the temperature gradients lead to vertical water vapour transport and a preferred direction of grain growth, or structural anisotropy (e.g. Colbeck, 1983; Lytle and Jezek, 1994). Seismic anisotropy can also occur where alternating ice layers with different densities are present, even if those layers are otherwise isotropic. This is often referred to as effective anisotropy (e.g. Backus, 1962; Hörhold and others, 2009; Picotti and others, 2010; Diez and others, 2016).

Most physical properties of a single crystal of ice are anisotropic (Fletcher, 1970) and can be described relative to the orientation of the crystallographic $c$-axis, which is orthogonal to the basal plane. Compressional seismic waves travel $7 \%$ faster through an ice crystal along the $c$-axis than orthogonal to it (Bennett, 1968). Despite the pronounced anisotropy of single ice crystals, a polycrystalline aggregate will behave isotropically provided that it has a statistically random distribution of $c$-axis orientations. When polycrystalline ice is subject to prolonged deformation under conditions of constant stress (as defined by the large-scale ice flow regime) its microstructure evolves, resulting in the development of a pattern of crystallographic $c$-axis orientations (fabric) that is compatible with the applied stress. This microstructural evolution makes the ice anisotropic and correspondingly easier to deform perpendicular to the $c$-axis compared to an isotropic aggregate (e.g. Budd and Jacka, 1989; Budd and others, 2013; Faria and others, 2014). Fabric evolution is a ubiquitous and important feature of polar ice sheets that develops due to multiple micro-scale deformation and recovery processes that are influenced by air and ice temperature, the stress configuration and its magnitude and the presence of impurities (e.g. Budd and Jacka, 1989; Faria and others, 2014; Hudleston, 2015). The extent of the anisotropy associated with the development of a crystal orientation fabric can be described by statistical analysis of the distribution of $c$-axis orientations. In this study, the ice and firn with a crystal orientation fabric will be referred to as exhibiting intrinsic anisotropy (following Thomsen, 1986; Picotti and others, 2015).

In polycrystalline ice, seismic velocity is sensitive to the degree of intrinsic anisotropy. Higher values occur for strong, single maximum fabrics where the mean $c$-axis orientation is parallel to the direction of the seismic wave propagation (Bennett, 1968; Bentley, 1971; Blankenship and Bentley, 1987; Diez and others, 2014). Observations of the directional differences in seismic velocity can be used to investigate large-scale patterns of $c$-axis alignment in ice sheets (Anandakrishnan and others, 1994; Picotti and others, 2015), or englacial reflections caused by sudden changes in crystal orientation fabric (Horgan and others, 2011; Vélez and others, 2016; Kluskiewicz and others, 2017).

This study focuses on using seismic refraction to investigate the firn structure on the hundreds of metres to kilometre-scale. We analyse the seismic structure at eleven survey sites on the Amery Ice Shelf, East Antarctica, to better capture the role of ice dynamics in the evolution of the observed firn. The surveyed region spans the suture zone in-between two major ice flow units of the Amery Ice Shelf, those from the Mawson Escarpment Ice Stream and Lambert Glacier. We identify variations in firn structure and anisotropy both along and across the suture zone. Using orthogonal profiles at each site we investigate the distribution of seismic anisotropy (directional dependence of seismic velocity) in the firn of the region. Noting that there are relatively few previous investigations of firn structure, this study will further improve our understanding of how firn structure evolves in a highly dynamic region, a significant step towards improving icesheet mass-balance estimates.

\section{Data and methods}

\section{Data acquisition}

The dataset consists of orthogonal shallow seismic refraction profiles, acquired at eleven individual survey sites across the central part of the Amery Ice Shelf during the 2004-05 austral summer (Fig. 1, DOI: 10.25959/5e52efd1ab9e7). They target the region near the suture zone between the Mawson Escarpment Ice Stream and Lambert Glacier ice flow units. The survey sites are located $\sim 150 \mathrm{~km}$ downstream of the region where the Mawson Escarpment Ice Stream unit enters the Amery Ice Shelf. The region upstream of the survey sites is characterised by zones of elevated strain rates (Young and Hyland, 2002) and extensive blue ice zones (Phillips, 1998; Hui and others, 2014), which are shown in Figure 1. Nine of the sites are clustered into three sample areas along the boundary between the two ice flow units and are designated as upstream, midstream and downstream in this study. The field team surveyed three flowlines (one on the Mawson Escarpment Ice Stream, one on the Lambert Glacier ice flow units and one on the suture zone in-between these) at each sample area. The surveyed flowlines are $\sim 1 \mathrm{~km}$ apart. When discussing findings at, or in between, survey sites their names will be abbreviated according to their flowline, following Figure 1 (LG, SZ, ME). In discussions of glaciological implications, full names will be used.

Two additional sites, near the centre of each ice flow unit, complement the survey, where the expected simple shear strain rates are significantly lower. The survey sites were chosen using Landsat satellite images and the surface strain data of Young and Hyland (2002). The field team acquired two shallow seismic refraction profiles at each site, with one oriented along-flow (approximately $\mathrm{N}-\mathrm{S}$ ) and the other oriented across-flow (approximately E-W). Each profile comprised of a 24 channel geophone spread with groups of four $14 \mathrm{~Hz}$ geophones. The sources were Orica Pentex (110 g) charges, detonated along the seismic profile to provide continuous and overlapping coverage from -480 to $+480 \mathrm{~m}$ offset with a variable receiver spacing averaging $5 \mathrm{~m}$ for offsets $<100 \mathrm{~m}$ and a spacing of $10 \mathrm{~m}$ thereafter. The seismic dataset consists of $2.048 \mathrm{~s}$ records at a $4000 \mathrm{~Hz}$ sample rate. The along-flow and across-flow seismic profiles intersect at the centres of each profile.

We picked the first arrival travel times manually for each of the shallow seismic refraction profiles. At all sites misplacements of shot locations of up to $3 \mathrm{~m}$ lead to uncertainties of up to 0.45 $\mathrm{ms}$. Signal to noise ratio was generally high and wavelets clearly exposed, so that the cumulative picking uncertainties are an order of magnitude smaller than the shot location misplacements. In agreement with Brisbourne and others (2014), we therefore estimate picking uncertainty to generally be better than $\sim 0.5 \mathrm{~ms}$.

\section{Velocity-depth inversion from seismic travel times}

We apply the 1-D velocity-depth inversion developed by Wiechert-Herglotz-Bateman (WHB) (Slichter, 1932) to the dataset. This approach assumes that the seismic velocity increases monotonically with depth, seismic layers are horizontally flat 


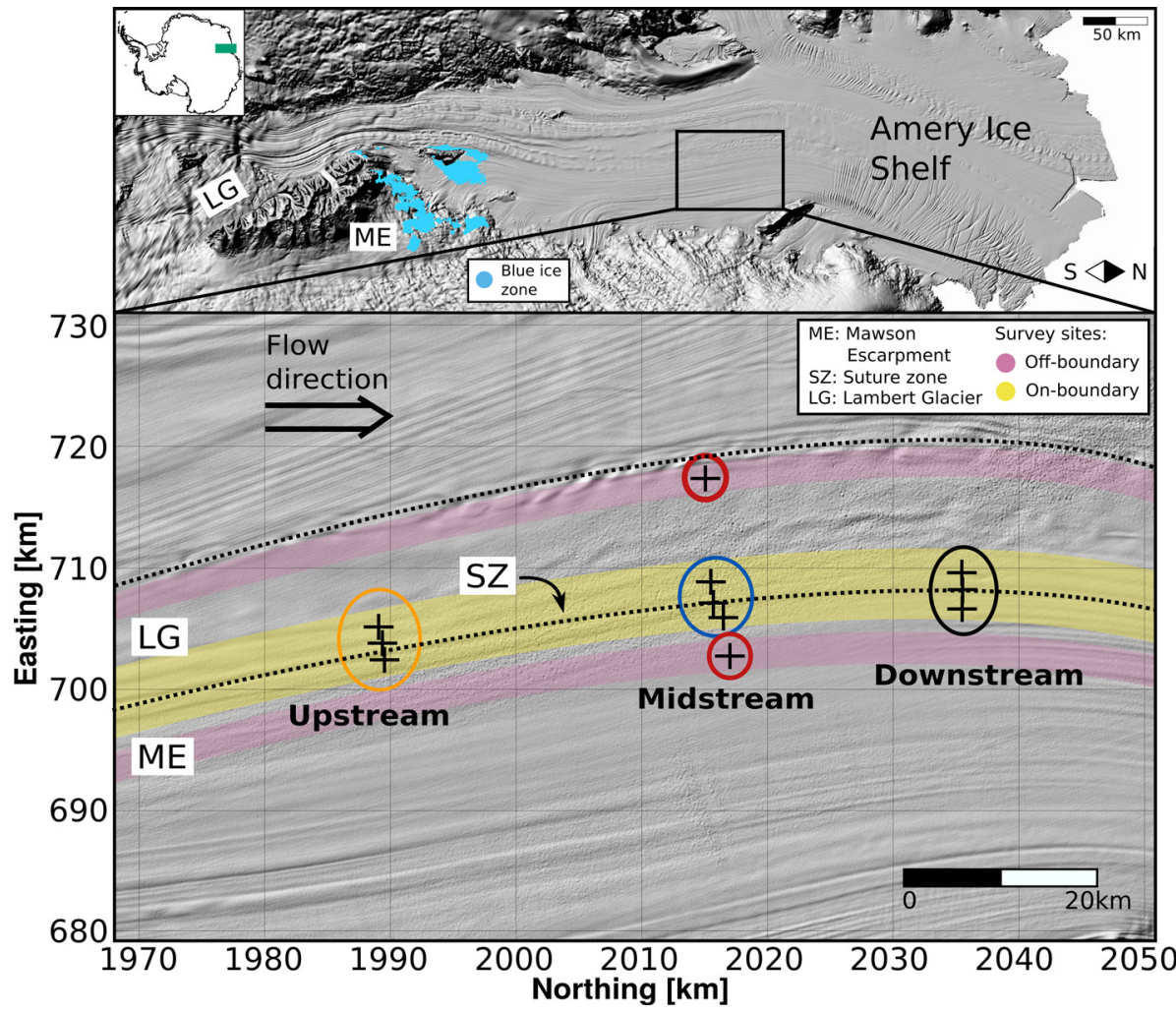

Fig. 1. Map of the Amery Ice Shelf and seismic survey region. Top: Amery Ice Shelf surface morphology, with the inset of ice shelf location. The blue ice zones upstream of the survey sites are highlighted (Hui and others, 2014). Bottom: Details of study area. The three sample areas are highlighted by circles in orange (upstream), blue (midstream) and black (downstream); ME: Mawson Escarpment Ice Stream; SZ: suture zone; LG: Lambert Glacier, off-boundary sites (named ME East and LG West) are highlighted by circles in red; coordinates in Universal Polar Stereographic (ref. latitude: -71); approximate boundaries of relevant ice units are shown by black dashed lines. DEMs courtesy of the Polar Geospatial Center (Howat and others, 2019). and the firn only varies in one dimension within a profile (lateral homogeneity on a scale of $100 \mathrm{~s}$ of metres). We verified the lateral homogeneity of our seismic profiles by comparing the first arrival travel times along the forward and reverse shot directions of each profile (Appendix A). The travel time differences are mostly smaller than the picking uncertainty, hence we assume each profile to be laterally homogeneous.

This allows us to apply the WHB technique to the dataset, where the seismic travel time curve of the first arrivals is a function of the seismic velocity and penetration depth of the diving waves (Slichter, 1932):

$$
z(u)=\frac{1}{\pi} \int_{0}^{x(u)} \cosh ^{-1}\left(\frac{P}{u}\right) \mathrm{d} x
$$

where $x$ is the source-to-receiver offset (in $\mathrm{m}$ ), $u$ the slowness at offset $x$ with $x \leq X(u)$ (in $\mathrm{s} \mathrm{m}^{-1}$ ), $P$ the slowness at offset $X(u)$ (in $\mathrm{s} \mathrm{m}^{-1}$ ) and $z$ the associated depth (in $\mathrm{m}$ ). This inversion method is employed to calculate the seismic velocity structure at the 11 sites across the Amery Ice Shelf.

The WHB inversion requires uniform sampling of the seismic slowness in the source-to-receiver offset domain. We therefore employed the exponential equation derived by Kirchner and Bentley (1979) to produce a uniformly sampled travel time curve from the measured first arrival travel times:

$$
t(x)=a_{1}\left(1-\mathrm{e}^{-a_{2} x}\right)+a_{3}\left(1-\mathrm{e}^{-a_{4} x}\right)+a_{5} x,
$$

where $x$ is the offset, $t$ is the travel time and $a_{i}, i \in[1,5]$, are constants relating to the curvature of the travel time data. The $a_{i}$ values are determined by estimating the best-fit regression to the travel time data using the trust region reflective method (More and Sorensen, 1983). The approximation is then used to eliminate outliers from the original data before repeating the travel time approximation. Differences larger than $2 \mathrm{~ms}$ between the picked and the approximated travel time, presumably due to incorrect geophone placements, are considered outliers, as they imply a physically unrealistic increase in firn density. Removed data points are randomly distributed along the profiles and account for $<1 \%$ of the data. The seismic velocities are then determined by differentiating and inverting $t(x)$ (Eqn (3)). The associated depths were calculated using WHB method, following Eqn (1):

$$
v(x)=\left[\frac{\mathrm{d} t(x)}{\mathrm{d} x}\right]^{-1}=\left[a_{1} a_{2} \mathrm{e}^{-a_{2} x}+a_{3} a_{4} \mathrm{e}^{-a_{4} x}+a_{5}\right]^{-1}
$$

We performed sensitivity tests of the travel time picks to determine the impact of the picking uncertainties on the resultant seismic velocity-depth profiles. We applied the picking uncertainty to the travel time in the following ways: (1) constant offset with maximum uncertainty (positive and negative); (2) linearly increasing uncertainty (from -0.5 to $0.5 \mathrm{~ms}$ ), and linearly decreasing uncertainty (from 0.5 to $-0.5 \mathrm{~ms}$ ) and (3) linearly increasing (from -0.5 to $0.5 \mathrm{~ms}$ ) uncertainty for offsets $>100$ $\mathrm{m}$ and linearly decreasing (from 0.5 to $-0.5 \mathrm{~ms}$ ) uncertainty for offsets $>100 \mathrm{~m}$. (4) Additionally, we directly accounted for the shot location misplacement by adding (or subtracting) the offset error of $3 \mathrm{~m}$ between 30 and $360 \mathrm{~m}$, in accordance with our findings. The travel time remained unchanged for this test. The range of the resultant velocity-depth values (difference between minimum and maximum at each offset) is then used as the model error to the picking uncertainty (see Appendix B for more information).

\section{Results}

\section{Travel times}

The overall spread and the std dev. of observed first arrival travel times of each of the three sample areas (excluding the two offboundary sites) and their related offset are shown in Figure 2a, following the colour coding of Figure 1. The near-offset travel 

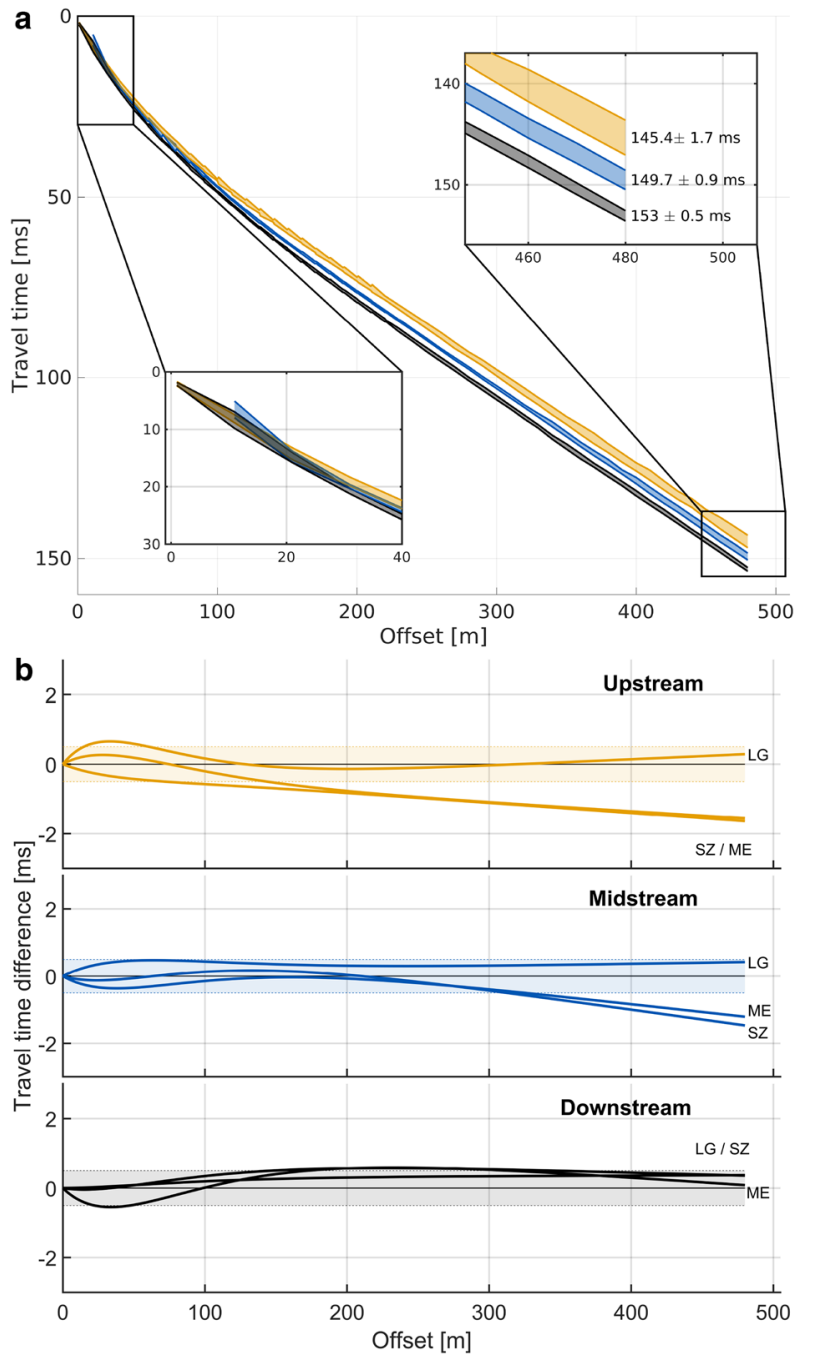

Fig. 2. (a) Spread of picked travel times vs offset for the three sample areas on the Amery Ice Shelf, off-boundary sites excluded. The minimum and maximum travel time values within each sample area are shown by lines; insets show the nearand far-offset values in more detail; the inset for far-offsets shows the average travel time and std dev. of first arrival travel times at maximum offset of each survey area. (b) Travel time differences between the along- and across-flow profiles for all of the survey sites (off-boundary sites excluded). Positive values indicate longer along-flow travel times compared to across-flow travel times, whereas negative values indicate shorter along-flow travel times compared to across-flow travel times. Thin black lines indicate the zero value. Shaded regions represent travel time uncertainty. Colour coding follows Figure 1.

times appear to be uniformly distributed among the survey areas and possess considerable overlap (left inset). They begin to deviate at $\sim 80 \mathrm{~m}$ offset and remain separated until maximum offset (right inset), with the upstream area possessing the smallest and the downstream area possessing the largest absolute travel times. The travel time std dev. is the largest within the upstream area with $1.7 \mathrm{~ms}$ and the smallest within the downstream area with $0.5 \mathrm{~ms}$.

The travel time differences between the along-flow and acrossflow profiles of the nine survey sites near the suture zone (no offboundary sites) are shown in Figure $2 \mathrm{~b}$, with the $0.5 \mathrm{~ms}$ travel time uncertainty shown as shaded areas. The approximated travel times (Eqn (2)) are shown for clarity. The ME and SZ flowlines exhibit travel time differences larger than the travel time uncertainty at the large offsets for the upstream and midstream areas. The travel time differences of the LG flowline remain below the picking uncertainty at all of the sample areas.

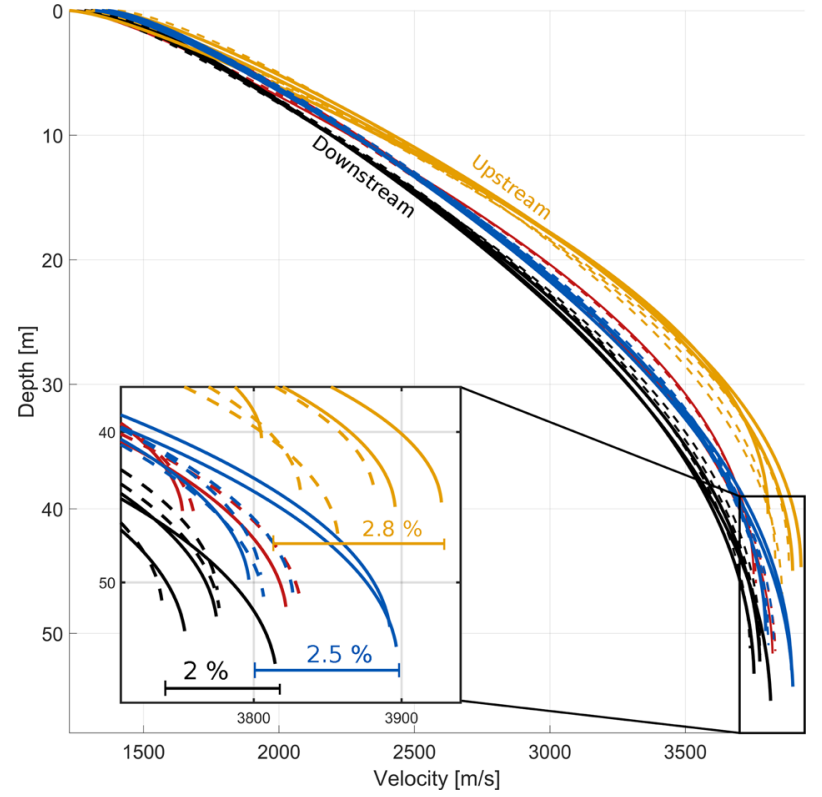

Fig. 3. Velocity-depth profiles for all of the survey sites on the Amery Ice Shelf. Each survey site is represented by two velocity-depth curves. Across-flow profiles are shown as solid lines and along-flow profiles are shown as dashed lines. The inset shows the seismic velocities at maximum depth as well as the relative range of seismic velocities of each on-boundary sample area. Colour coding follows Figure 1.

\section{Velocity profiles}

Figure 3 shows the velocity-depth profiles for all of the survey sites. The two main trends of the travel times (Fig. 2a), (i) the increase of absolute travel time, and (ii) the decrease in the range of travel times from up- to downstream, are also visible here. There are two velocity-depth profiles for each survey site, one in the along-flow direction (see inset, dashed lines) and one in the across-flow direction (solid lines). There is no separation of the travel times of the three sample areas near the surface. The separation starts at $5-10 \mathrm{~m}$ depth, which corresponds to 30-50 m offset. After a strong separation phase at intermediate depths of 10 to $40 \mathrm{~m}$, the seismic velocities exhibit minimal overlap close to the maximum penetration depth (45-55 m depth, depending on site). At equivalent depths the seismic velocities are highest at the upstream sites, followed by the midstream and then downstream sites. The picking uncertainty of $\pm 0.5 \mathrm{~ms}$ converts to a maximum modelled velocity error of $2.4 \%$ (or $\pm 45 \mathrm{~m} \mathrm{~s}^{-1}$ ) at maximum penetration depth. The along-flow and across-flow profiles of most sites exhibit significant differences in seismic velocity, but below the conservatively chosen model error. Although the firn/ice transition zone is located at the same depth for orthogonal profiles of the same survey site, we note differences in the maximum penetration depth of up to $5 \mathrm{~m}$ at individual sites. The penetration depth increases by $\sim 8$ $\mathrm{m}$ from 44 to $52 \mathrm{~m}$ along the flow direction of the Amery Ice Shelf, and the average seismic velocity at the maximum depth decreases by $\sim 90 \mathrm{~m} \mathrm{~s}^{-1}$. The across-flow seismic velocities are generally larger than the along-flow velocities. The magnitude of both of these trends in seismic velocity is smaller than the model error of $\pm 45 \mathrm{~m} \mathrm{~s}^{-1}$, but is consistent with the observed travel times (Fig. 2a).

\section{Velocity-depth values close to the firn/ice transition zone}

When comparing velocity-depth values at maximum offset, which we take to be close to the firn/ice transition zone, we observe a distinct grouping according to their position along 


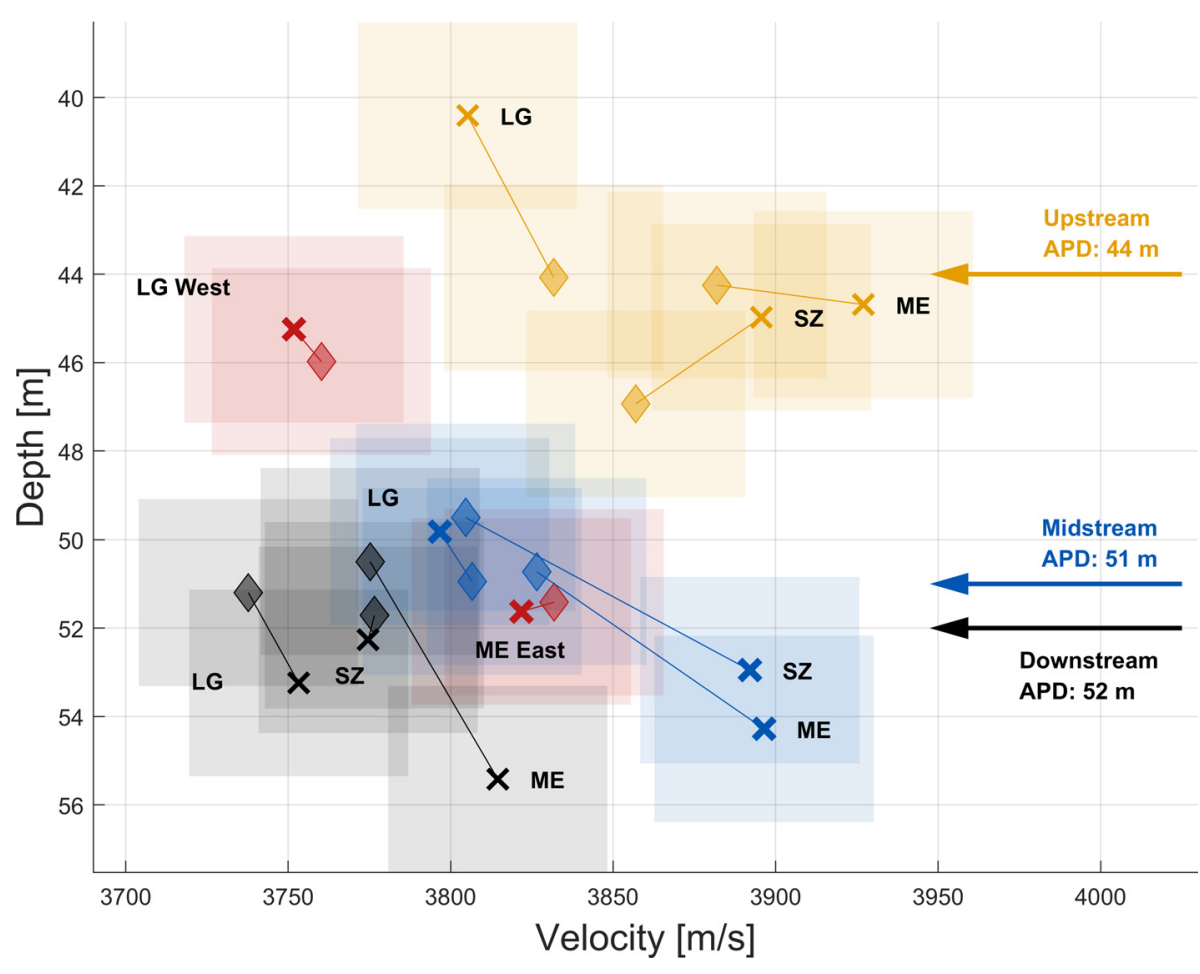

Fig. 4. Velocity-depth values of all survey sites on the Amery Ice Shelf close to the firn/ice transition zone (maximum penetration depth). For each survey site there are two values in each plot: along-flow values are marked by diamonds, across-flow values by crosses. Profiles for each site are connected with a line. The site location is displayed next to the acrossboundary value of each pair (crosses). This plot should be used to compare location groups rather than single survey sites due to the significant uncertainties in seismic velocity. APD: average penetration depth of the survey area, i.e. up-, mid- or downstream. Colour coding and abbreviations follow Figure 1, with ME East: Mawson Escarpment Ice Stream off-boundary site and LG West: Lambert Glacier off-boundary site. Black circles indicate the separation of ice flow units and shaded areas show the model error. the flowline (Fig. 4). The upstream sample area exhibits the fastest seismic velocities, followed by midstream and then the downstream sample area. The upstream sample area on average exhibits the smallest penetration depths (Fig. 4), followed by midstream and then downstream with the deepest penetration depths. A comparison of the seismic velocities of the sampled flowlines with one another (Fig. 4), highlights an overlap between the survey sites on the ME and SZ flowlines, whereas the sites on the LG flowline stand out due to slower seismic velocities and, upstream and midstream, slightly shallower penetration depths (Fig. 4). The two off-boundary sites 'ME East' and 'LG West' also agree with this observation. Their velocity-depth values coincide with their corresponding flowlines, ME and LG respectively.

\section{Discussion}

The seismic dataset used in this study consists of 11 individual survey sites along and across the suture zone of two major ice flow units of the Amery Ice Shelf. Sampling the ME, SZ and LG flowlines at three different locations enables the analysis of trends both parallel and orthogonal to the flow direction.

\section{Uncertainties}

The travel time uncertainty of this dataset, and with it the resulting error in modelled seismic velocity and penetration depth, is comparatively high for a seismic refraction survey, likely due to the incorrect placement of some shot locations of up to $3 \mathrm{~m}$. The travel time uncertainty was chosen conservatively (i.e. high) to bolster the significance and informative value of any differences that exceed the uncertainty threshold. Differences in seismic velocity between individual survey sites are usually smaller than the model error of $\pm 45 \mathrm{~m} \mathrm{~s}^{-1}$ ) (see overlap of shaded areas in Fig. 4), preventing statistically meaningful comparison of differences between individual sites in this study.

However, the consistency of some trends throughout the dataset provides an insight into the characteristics of the firn. We discuss these trends here, separated into differences along and across the flow direction, to highlight the complexity of the firn structure of the region. The analysis of these trends will focus on the deep firn layer (Fig. 4), as the cause of the apparently more uniform distribution of velocity-depth values near the surface (Fig. 3) cannot be unambiguously determined in this study for two key reasons:

(1) The near-offset $(<100 \mathrm{~m})$ receiver spacing of $\sim 5 \mathrm{~m}$ may not adequately capture the fast densification with depth near the surface.

(2) Near the surface the firn density can vary up to $\pm 80 \mathrm{~kg} \mathrm{~m}^{-3}$ on scales of centimetres to metres (e.g. Freitag and others, 2004; Hörhold and others, 2011) and with it the seismic velocity by $50-90 \mathrm{~m} \mathrm{~s}^{-1}$, for the corresponding density range (Kohnen, 1972). The metre-scale vertical resolution of the seismic data is significantly larger than the thickness of most ice lenses, and the travel time approximation (Kirchner and Bentley, 1979) has an additional smoothing effect on the data. If present, high density layers would not be individually resolved and would instead result in an effective seismic anisotropy (Backus, 1962).

We therefore focus on analysing the deeper layers, where the issues described above are of less concern. Due to lateral homogeneity of opposite shot directions for the same profile, the seismic waves of along- and across-flow profiles should travel through the same firn and, within uncertainty, yield the same velocity-depth profiles and penetration depths. We assume that the depth differences of up to $5 \mathrm{~m}$ for individual survey sites (Fig. 4) are caused by a combination of the model error and the seismic anisotropy of the firn. In polycrystalline ice, the seismic P-wave velocity can vary by up to $7 \%$ due to a preferred crystal orientation fabric (Bennett, 1968) which leads to miscalculations of the penetration depth of the same magnitude for seismic reflection surveys in polycrystalline ice (Diez and others, 2014). For a $50 \mathrm{~m}$ thick ice layer this translates to penetration depth differences of up to $3.5 \mathrm{~m}$. This prohibits a quantitative analysis of the velocities at maximum penetration depth of individual survey sites. Instead, the velocity-depth profiles are used to highlight 
differences and similarities between the three survey regions in the 2-D velocity-depth space (Fig. 4).

\section{Along-flow trends}

The average seismic travel time at the maximum offset (Fig. 1) increases from $0.145 \mathrm{~s}$ upstream to $0.153 \mathrm{~s}$ downstream. This coincides with an average decrease in seismic velocity at maximum penetration depth from $3866 \mathrm{~m} \mathrm{~s}^{-1}$ upstream to $3771 \mathrm{~m} \mathrm{~s}^{-1}$ downstream (Figs 2a and 3 ). This decrease in seismic velocity further coincides with an overall increase in penetration depth from $44 \mathrm{~m}$ at the upstream sites to $52 \mathrm{~m}$ downstream sites (Fig. 3), or an average increase in firn thickness of $1 \mathrm{~m}$ per $6 \mathrm{~km}$.

The firn also appears to undergo a process of homogenisation from the upstream to the downstream sample area. When comparing the travel times of profiles oriented both in the alongand across-flow directions of different survey areas with each other we note a decrease in the std dev. of travel times from $1.7 \mathrm{~ms}$ upstream to $0.5 \mathrm{~ms}$ downstream (Fig. 2 inset far offsets). This decrease is accompanied by a decrease in the range of seismic velocities from 2.8 to $2 \%$ (Fig. 3 , inset). We interpret this as the physical structure of the firn becoming more homogeneous from upstream to downstream.

\section{Across-flow trends}

Aggregating survey sites along their respective flowlines (three sites per flowline) enables the identification of trends in the firn structure across the flow direction, i.e. between Mawson Escarpment Ice Stream flow unit, the suture zone and the Lambert Glacier ice flow unit. We find differences in travel times, penetration depths and seismic velocities. Firstly, the travel time differences above the uncertainty of $\pm 0.5 \mathrm{~ms}$ are only present on the ME and SZ flowlines (Fig. 2b). Secondly, the survey sites on the LG flowline are characterised by slower seismic velocities and slightly shallower penetration depths than the Mawson Escarpment Ice Stream and suture zone sites (Fig. 4), suggesting a separation of the firn structure along the suture zone of the two ice flow units.

The differences in penetration depth could be due to differences in the thickness of the firn, as the units originate from very different regions. Firn thickness differences across the boundary could therefore originate from a discontinuous step-like ice thickness change in the across-flow direction. This does however not explain the change in the degree of seismic anisotropy we observe to be associated with the firn thickness change, which suggests that the boundary between these two ice flow units of the eastern Amery Ice Shelf is also a boundary in the seismic structure of the firn.

\section{Seismic anisotropy}

Since seismic diving waves of orthogonal profiles at the same site sample the same firn region, the observed differences in travel time must be due to the measurement uncertainty or the directional dependence of seismic velocity in the firn, i.e. seismic anisotropy. The travel time differences for orthogonal profiles exceed the travel time uncertainty of $\pm 0.5 \mathrm{~ms}$ at four survey sites, i.e. the $\mathrm{ME}$ and $\mathrm{SZ}$ flowlines at the upstream and midstream sample areas (Fig. 2b). Travel time differences are caused by seismic velocity differences along the ray path. Using WHB we calculated the ray paths of the along- and across-flow profiles at these survey sites. From the travel times we conclude that at all four sites (ME upstream, ME midstream; SZ upstream, SZ midstream) the average seismic velocity is faster in the across-flow direction, as indicated by negative travel time differences in Figure $2 b$.
This, in combination with the apparent firn thickness change that is present at the same four survey sites, suggests that the boundary between these two ice flow units of the eastern Amery Ice Shelf is also a boundary in the seismic structure of the firn. Although the velocity-depth profiles (Figs 3 and 4) could provide insight into the degree of seismic anisotropy and its development with depth, the relatively high model uncertainty of $45 \mathrm{~m} \mathrm{~s}^{-1}$ and penetration depth differences of up to $5 \mathrm{~m}$ prevent such an analysis.

The large-scale flow regime of the survey region is transverse simple shear (Young and Hyland, 2002). Here, a combination of the direction of the compressive principal axis of the shear strain and rigid-body rotation leads to a horizontal single maximum crystal orientation fabric, oriented between 45 and $90^{\circ}$ away from the shear margin (Alley, 1988; Budd and Jacka, 1989; Fujita and Mae, 1994).

The direction of faster seismic velocity is therefore consistent with the large-scale dynamics of the Amery Ice Shelf (Bennett, 1968; Diez and others, 2014), although the two orthogonal seismic profiles per site likely do not capture the maximum degree of seismic anisotropy, as the single maximum crystal orientation fabric is likely oriented somewhere in between the two. Although the cause of this seismic anisotropy cannot be unambiguously determined on the basis of a seismic refraction study alone, the fabric that is expected along the underlying suture zone ( $>45^{\circ}$ away from the shear margin) is consistent with the seismic findings in that the seismic velocity is faster across-flow for the LG, SZ survey sites of the upstream and midstream regions. This leaves the possibility open that the large-scale flow regime of the region plays a role in the development of the seismic anisotropy in the firn. However, if the large-scale flow regime was the dominant factor in the development of anisotropy in the firn, it should be evident at more survey sites near the suture zone, implying that other processes must be involved in the development and disappearance of seismic anisotropy in the firn.

\section{Seismic anisotropy in the firn and its connection to the flow regime}

Although there are some indications for a connection between the physical structure of the firn and the large-scale ice shelf dynamics of the region, the extent to which the flow regime of the ice masses can influence firn evolution is not clear (Salamatin and others, 2009; Faria and others, 2014). For the deeper ice, beneath the firn, many studies demonstrate the connection between large-scale ice dynamics and the development of fabric in ice (e.g. see the reviews of Budd and Jacka, 1989; Hudleston, 2015), but to the best of our knowledge there has not been a definitive study illustrating their influence on the intrinsic anisotropy of firn. Jordan and others (2020) show that on Whillans Ice Stream a clear shift in the prevailing c-axis orientation is present between the near-surface layers and the deeper ice. However, in this case the deeper fabric is a result of the ice reacting to the presence of a nearby sticky spot, which limits the comparability. To investigate the possible effect of the underlying ice dynamics of the Amery Ice Shelf on the development of anisotropy in firn, we calculated the strain that could have accumulated in the firn due to the large-scale flow of the ice shelf. We base our strain estimation on Antarctica wide velocity and strain rate mosaics derived from Landsat imagery (Rignot and others, 2011; Mouginot and others, 2012; Fahnestock and others, 2016; Alley and others, 2018). The presence of a major blue ice zone upstream of the study area represents a limit for where the snow accumulation of the firn sampled for this study commenced. Integrating the strain rate for each survey site along the flowline upstream to the blue ice zone provides a maximum value for the component of 
accumulated strain in the firn that could be due to the large-scale dynamics of the ice shelf (Phillips, 1998; Hui and others, 2014). We find that the maximum accumulated strain along these flowlines is $\sim 0.9 \%$, and therefore approximately an order of magnitude below that generally required for large-scale ice dynamics to produce intrinsic anisotropy in the polycrystalline ice (Treverrow and others, 2012). Laboratory studies indicate that for ice with density $\geq 830 \mathrm{~kg} \mathrm{~m}^{-3}$, the strain required to produce a fabric in material with no pre-existing anisotropy is $\geq 10 \%$ (e.g. Budd and Jacka, 1989; Treverrow and others, 2012; Craw and others, 2018). Ice core analyses demonstrate that clear anisotropic fabrics can be present close to the firn/ice transition zone (e.g. Svensson and others, 2003; Wang and others, 2003; Montagnat and others, 2014; Treverrow and others, 2016), indicating that their development commenced within the firn at these sites.

Due to contact between firn and the underlying ice the firn must be compliant to deformation occurring in the underlying ice (Salamatin and others, 2009). Furthermore, Faria and others (2014) describe how densification processes within firn can produce strains high enough to generate tertiary creep over small spatial scales as the firn responds to highly localised variations in the stress field. Due to their localised nature, these deformations may not be consistent with the large-scale stress regime imposed by the ice shelf dynamics. Nevertheless, these processes provide conceptual support for the role of deformation in the development of intrinsic anisotropy within firn. In future studies, a suite of firn and snow observations would be required to identify the microscale processes that contribute to this anisotropy and its connection to seismic anisotropy.

Additional research is clearly required to understand firn evolution processes and reduce the ambiguity inherent to seismic refraction measurements. Where possible, we suggest that future seismic studies of firn structure should incorporate a range of complementary measurements. In addition to multi-angle seismic profiles, observations should ideally include cores that recover the firn and firn-ice transition zones, vertical strain rate information from phase-sensitive radar (e.g. Brisbourne and others, 2019) and surface GPS in order to characterise the contributions of strain and densification to firn evolution. To minimise uncertainty these measurements should be made in a zone where the upstream flow regime is both stable and consistent with conditions at the survey site. Such a study would address (i) if the seismic anisotropy present in deep firn layers originates from intrinsic anisotropy and (ii) to what extent the firn anisotropy is consistent with anisotropy present in the uppermost ice layers below the firn. In turn a better understanding of how firn evolves will contribute to reducing uncertainty in estimates of ice-sheet mass balance and the depth-age relationship in ice core climatological records.

\section{Conclusions}

We demonstrate the complex physical structure of the firn layer on the Amery Ice Shelf by analysing first arrival travel times of a seismic dataset, which reveals clear trends along and across a major ice shelf suture zone. Orthogonal profiles at each of the 11 survey sites permit the analysis of directional changes of seismic velocity (seismic anisotropy) at each site and relative seismic velocity changes between the survey sites. We observe a gradual increase of firn thickness in the downstream direction across the surveyed region. The suture zone between ice flow units appears to represent a boundary in the firn structure, with distinct firn thicknesses and average seismic velocities for each ice flow unit. At four survey sites we find travel time differences between orthogonal profiles above the picking error, which indicates a directional dependence of the average seismic velocity, i.e. seismic anisotropy, in the firn column.

Where present, the faster direction of seismic velocity does not contradict the crystal orientation fabric that is expected to be present in the underlying ice mass due to the large-scale flow regime. While this suggests that glacier dynamics may play a role in the development of firn structure, the extent to which deformation of the underlying ice mass can influence the development of the firn structure remains poorly understood. We demonstrate the feasibility of employing seismic methods to characterise the evolution of the firn in detail over large spatial scales, particularly where coring may not be feasible. However, to further understand the characteristics of firn, and to what extent this can be achieved by seismic methods, future seismic surveys should be complemented with other sampling approaches (e.g. firn coring, radar and GPS).

Acknowledgments. This research was supported under Australian Research Council's Special Research Initiative for Antarctic Gateway Partnership (Project ID SR140300001). The seismic survey was supported by the Australian Antarctic Division (AAD) ASAC Project 2581 with Richard Coleman as Chief Investigator. Data from the 2004/05 seismic survey can be found on the data portal of the Institute for Marine and Antarctic Studies, University of Tasmania (http://dx.doi.org/doi:10.25959/5e52efdlab9e7), or via contacting the authors. We thank Alex Brisbourne, Coen Hofstede and the editor for thoughtful reviews which improved the manuscript. We also thank Christopher Watson and Richard Coleman for providing advice and assistance.

\section{References}

Alley RB (1980) Densification and Recrystallization of Firn at Dome C, Central East Antarctica (Ph.D. thesis). The Ohio State University.

Alley RB (1987a) Firn densification by grain-boundary sliding: a first model. Journal de Physique Colloques 48(C1), 249-256.

Alley RB (1987b) Texture of polar firn for remote sensing. Annals of Glaciology 9, 1-4. doi: 10.3189/S0260305500200670.

Alley RB (1988) Fabrics in polar ice sheets: development and prediction. Science 240(4851), 493-495. doi: 10.1126/science.240.4851.493.

Alley KE and 5 others ( 2018) Continent-wide estimates of Antarctic strain rates from Landsat 8-derived velocity grids. Journal of Glaciology 64(244), 321-332. doi: 10.1017/jog.2018.23.

Alley RB and Bentley CR (1988) Ice-core analysis on the Siple Coast of West Antarctica. Annals of Glaciology 11, 1-7.

Anandakrishnan S, Fritzpatrick JJ, Alley RB, Gow AJ and Meese DA (1994) Shear-wave detection of asymmetric c-axis fabrics in the GISP2 ice core, Greenland. Journal of Glaciology 40(136), 491-496.

Backus GE (1962) Long-wave elastic anisotropy produced by horizontal layering. Journal of Geophysical Research 67(11), 4427-4440. doi: 10.1029/ JZ067i011p04427.

Bennett HF (1968) An Investigation into Velocity Anisotropy Through Measurements of Ultrasonic-wave Velocities in Snow and Ice Cores from Greenland and Antarctica (Ph.D. thesis). University of Wisconsin-Madison.

Bentley CR (1971) Seismic anisotropy of the West Antarctic ice sheet. Antarctic Snow and Ice Studies II 16, 131-177.

Blankenship DD and Bentley CR (1987) The crystalline fabric of polar ice sheets inferred from seismic anisotropy. The Physical Basis of Ice Sheet Modelling (Proceedings of the Vancouver Symposium), (170), 17-28.

Brisbourne AM and 5 others (2014) Seabed topography beneath Larsen C Ice Shelf from seismic soundings. The Cryosphere 8(1), 1-13. doi: 10.5194/ tc-8-1-2014.

Brisbourne AM and 5 others (2019) Constraining recent ice flow history at Korff Ice Rise, West Antarctica, using radar and seismic measurements of Ice Fabric. Journal of Geophysical Research: Earth Surface 124(1), 175-194. doi: 10.1029/2018JF004776.

Budd WF and Jacka TH (1989) A review of ice rheology for ice sheet modelling. Cold Regions Science and Technology 16(2), 107-144. doi: 10.1016/ 0165-232X(89)90014-1.

Budd WF, Warner RC, Jacka TH, Li J and Treverrow A (2013) Ice flow relations for stress and strain-rate components from combined shear and 
compression laboratory experiments. Journal of Glaciology 59(214), 374392. doi: 10.3189/2013JoG12J106.

Burton-Johnson A, Black M, Peter TF and Kaluza-Gilbert J (2016) An automated methodology for differentiating rock from snow, clouds and sea in Antarctica from Landsat 8 imagery: a new rock outcrop map and area estimation for the entire Antarctic continent. The Cryosphere 10(4), 1665-1677.

Colbeck SC (1983) Theory of metamorphism of dry snow. Journal of Geophysical Research 88(C9), 5475-5482. doi: 10.1029/JC088iC09p05475.

Craven M and Allison I (1998) Firnification and the effects of wind-packing on Antarctic snow. Annals of Glaciology 27, 239-245. doi: 10.3189/ 1998AoG27-1-239-245.

Craw L, Qi C, Prior DJ, Goldsby DL and Kim D (2018) Mechanics and microstructure of deformed natural anisotropic ice. Journal of Structural Geology 115, 152-166. doi: 10.1016/j.jsg.2018.07.014.

Cuffey KM and Paterson WSB (2010) The Physics of Glaciers, 4th Edn. Amsterdam: Academic Press.

Diez A and 7 others (2014) Influence of ice crystal anisotropy on seismic velocity analysis. Annals of Glaciology 55(67), 97-106. doi: 10.3189/ 2014AoG67A002.

Diez A and 8 others (2016) Ice shelf structure derived from dispersion curve analysis of ambient seismic noise, Ross Ice Shelf, Antarctica. Geophysical Journal International 205(2), 785-795. doi: 10.1093/gji/ggw036.

Diez A, Eisen O, Hofstede C, Bohleber P and Polom U (2013) Joint interpretation of explosive and vibroseismic surveys on cold firn for the investigation of ice properties. Annals of Glaciology 54(64), 201-210. doi: 10.3189/ 2013AoG64A200.

Ebinuma T, Maeno N and Maeno H (1987) Particle rearrangement and dislocation creep in a snow-densification process. Le Journal de Physique Colloques 48(C1), 263-269. doi: 10.1051/jphyscol:1987137.

Fahnestock MA and 5 others (2016) Rapid large-area mapping of ice flow using Landsat 8. Remote Sensing of Environment 185, 84-94. doi: 10. 1016/j.rse.2015.11.023.

Faria SH, Weikusat I and Azuma N (2014) The microstructure of polar ice. Part II: state of the art. Journal of Structural Geology 61, 21-49. doi: 10. 1016/j.jsg.2013.11.003

Fletcher NH (1970) The Chemical Physics of Ice. Cambridge: Cambridge University Press.

Freitag J, Kipfstuhl S and Faria SH (2008) The connectivity of crystallite agglomerates in low-density firn at Kohnen station, Dronning Maud Land, Antarctica. Annals of Glaciology 49, 114-120. doi: 10.3189/ 172756408787814852

Freitag J, Wilhelms F and Kipfstuhl S (2004) Microstructure-dependent densification of polar firn derived from X-ray microtomography. Journal of Glaciology 50(169), 243-250. doi: 10.3189/172756504781830123.

Fujita S and Mae S (1994) Strain in the ice sheet deduced from the crystalorientation fabrics from bare icefields adjacent to the Sor-Rondane Mountains, Dronning Maud Land, East Antarctica. Journal of Glaciology 40(134), 135-139. doi: 10.1017/S0022143000003907.

Fujita S, Okuyama J, Hori A and Hondoh T (2009) Metamorphism of stratified firn at Dome Fuji, Antarctica: a mechanism for local insolation modulation of gas transport conditions during bubble close off. Journal of Geophysical Research: Solid Earth 114(3), 1-21. doi: 10.1029/ 2008JF001143.

Helsen MM and 7 others (2008) Elevation changes in Antarctica mainly determined by accumulation variability. Science 320(5883), 1626-1629. doi: $10.1126 /$ science. 1153894 .

Herron MM and Langway CC (1980) Firn densification: an empirical model. Journal of Glaciology 25(93), 373-385. doi: 10.3189/S0022143000015239.

Hobbs PV and Mason BJ (1964) The sintering and adhesion of ice. Philosophical Magazine 9(98), 181-197. doi: 10.1080/14786436408229184.

Horgan HJ, Anandakrishnan S, Alley RB, Burkett PG and Peters LE (2011) Englacial seismic reflectivity: imaging crystal-orientation fabric in West Antarctica. Journal of Glaciology 57(204), 639-650. doi: 10.3189/ 002214311797409686.

Hörhold MW, Albert MR and Freitag J (2009) The impact of accumulation rate on anisotropy and air permeability of polar firn at a high-accumulation site. Journal of Glaciology 55(192), 625-630. doi: 10.3189/ 002214309789471021.

Hörhold MW, Kipfstuhl S, Wilhelms F, Freitag J and Frenzel A (2011) The densification of layered polar firn. Journal of Geophysical Research: Earth Surface 116(F1), 1-15. doi: 10.1029/2009JF001630.
Howat IM, Porter C, Smith BE, Noh MJ and Morin P (2019) The reference elevation model of Antarctica. The Cryosphere 13(2), 665-674. doi: 10.5194/ tc-13-665-2019.

Hudleston PJ (2015) Structures and fabrics in glacial ice: a review. Journal of Structural Geology 81, 1-27. doi: 10.1016/j.jsg.2015.09.003.

Hui F and 12 others (2014) Mapping blue-ice areas in Antarctica using ETM+ and MODIS data. Annals of Glaciology 55(66), 129-137. doi: 10.3189/ 2014AoG66A069.

Jordan TM, Schroeder DM, Elsworth CW and Siegfried MR (2020) Estimation of ice fabric within Whillans Ice Stream using polarimetric phase-sensitive radar sounding. Annals of Glaciology 61(81), 74-83. doi: 10.1017/aog.2020.6.

Kameda T, Shoji H, Kawada K, Watanabe O and Clausen HB (1994) An empirical relation between overburden pressure and firn density. Annals of Glaciology 20(2), 87-94. doi: 10.3189/172756494794587267.

King EC and Jarvis EP (2007) Use of shear waves to measure Poisson's ratio in polar firn. Journal of Environmental and Engineering Geophysics 12(1), $15-21$.

Kirchner JF and Bentley CR (1979) Seismic short-refraction studies on the Ross Ice Shelf, Antarctica. Journal of Glaciology 24(90), 313-319. doi: 10. 3189/S0022143000014830.

Kirchner JF and Bentley CR (1990) RIGGS III: seismic short-refraction studies using an analytical curve-fitting technique. Antarctic Research Series 42(5), 109-126.

Kluskiewicz D and 5 others (2017) Sonic methods for measuring crystal orientation fabric in ice, and results from the West Antarctic ice sheet (WAIS) Divide. Journal of Glaciology 63(240), 603-616. doi: 10.1017/jog. 2017.20.

Kohnen H (1972) Über die Beziehung zwischen seismischen Geschwindigkeiten und der Dichte in Firn und Eis. Zeitschrift für Geophysik 38(5), 925-935.

Kohnen H (1974) The temperature dependence of seismic waves. Journal of Glaciology 13(67), 144-147.

Lipenkov VY, Salamatin AN and Duval P (1997) Bubbly-ice densification in ice sheets II: applications. Journal of Glaciology 43(145), 397-407. doi: 10. 3189/S0022143000034973.

Lomonaco R, Albert MR and Baker I (2011) Microstructural evolution of fine-grained layers through the firn column at Summit, Greenland. Journal of Glaciology 57(204), 755-762. doi: 10.3189/002214311797409730.

Luciano GL and Albert MR (2002) Bidirectional permeability measurements of polar firn. Annals of Glaciology 35(1982), 63-66. doi: 10.3189/ 172756402781817095.

Lytle VI and Jezek KC (1994) Dielectric permittivity and scattering measurements of Greenland firn at 26.5-40 GHz. IEEE Transactions on Geoscience and Remote Sensing 32(2), 290-295. doi: 10.1109/36.295044.

Maeno N and Ebinuma T (1983) Pressure sintering of ice and its implication to the densification of snow at Polar Glaciers and Ice Sheets. Journal of Physical Chemistry 87(21), 4103-4110. doi: 10.1021/j100244a023.

Montagnat $\mathbf{M}$ and 9 others (2014) Fabric along the NEEM ice core, Greenland, and its comparison with GRIP and NGRIP ice cores. The Cryosphere 8(4), 1129-1138. doi: 10.5194/tc-8-1129-2014.

More JJ and Sorensen DC (1983) Computing a trust region step. Society for Industrial and Applied Mathematics 4(3), 553-572.

Mouginot J, Scheuchl B and Rignot E (2012) Mapping of ice motion in Antarctica using synthetic-aperture radar data. Remote Sensing 4(9), 2753-2767. doi: 10.3390/rs4092753.

Parrenin F and 8 others (2012) On the gas-ice depth difference ( $\Delta$ depth) along the EPICA Dome C ice core. Climate of the Past 8(4), 1239-1255. doi: 10.5194/cp-8-1239-2012.

Phillips HA (1998) Surface meltstreams on the Amery Ice Shelf, East Antarctica. Annals of Glaciology 27, 177-181. doi: 10.3189/ 1998AoG27-1-177-181.

Picotti S, Carcione JM, Santos JE and Gei D (2010) Q-anisotropy in finelylayered media. Geophysical Research Letters 37(6), 1-6. doi: 10.1029/ 2009GL042046.

Picotti S, Vuan A, Carcione JM, Horgan HJ and Anandakrishnan S (2015) Anisotropy and crystalline fabric of Whillans Ice Stream (West Antarctica) inferred from multicomponent seismic data. Journal of Geophysical Research B: Solid Earth 120(6), 4237-4262.

Rignot E, Mouginot J and Scheuchl B (2011) Ice flow of the Antarctic Ice Sheet. Science 333(6048), 1427-1430. doi: 10.1126/science.1208336. 
Riverman KL and 7 others (2019) Enhanced firn densification in highaccumulation shear margins of the NE Greenland Ice Stream. Journal of Geophysical Research: Earth Surface 124(2), 365-382. doi: 10.1029/ 2017jf004604.

Salamatin AN and 5 others (2009) Snow/firn densification in Polar ice sheets. In Hondoh, T ed. Physics of Ice Core Records II, vol. 68. Sapporo, Japan: Institute of Low Temperature Science, Hokkaido University, pp. 195-222.

Schlegel R and 8 others (2019) Comparison of elastic moduli from seismic diving-wave and ice-core microstructure analysis in Antarctic polar firn. Annals of Glaciology 60(79), 220-230. doi: 10.1017/aog.2019.10.

Shepherd AP and 46 others (2012) A reconciled estimate of ice-sheet mass balance. Science 338(6111), 1183-1189. doi: 10.1126/science.1228102.

Slichter LB (1932) The theory of the interpretation of seismic travel-time curves in horizontal structures. Physics 3(6), 273-295. doi: 10.1063/1. 1745133.

Svensson A and 6 others (2003) Properties of ice crystals in NorthGRIP late to middle-Holocene ice. Annals of Glaciology 37, 113-118. doi: 10.3189/ 172756403781815636.

Thomsen L (1986) Weak elastic anisotropy. Geophysics 51(10), 1954-1966.

Treverrow A, Budd WF, Jacka TH and Warner RC (2012) The tertiary creep of polycrystalline ice: experimental evidence for stress-dependent levels of strain-rate enhancement. Journal of Glaciology 58(208), 301-314. doi: 10. 3189/2012JoG11J149.

Treverrow A, Jun L and Jacka TH (2016) Ice crystal $c$-axis orientation and mean grain size measurements from the Dome Summit South ice core, Law Dome, East Antarctica. Earth System Science Data 8(1), 253-263. doi: 10.5194/essd-8-253-2016.

Vélez JA, Tsoflias GP, Black RA, Van der Veen CJ and Anandakrishnan S (2016) Distribution of preferred ice crystal orientation determined from seismic anisotropy: evidence from Jakobshavn Isbræ and the North Greenland Eemian Ice Drilling facility, Greenland. Geophysics 81(1), W111-W118. doi: 10.1190/geo2015-0154.1.

Wang Y, Kipfstuhl S, Azuma N, Thorsteinsson T and Miller H (2003) Ice-fabrics study in the upper $1500 \mathrm{~m}$ of the Dome C (East Antarctica) deep ice core. Annals of Glaciology 37, 97-104. doi: 10.3189/ 172756403781816031.

Winther JG, Jespersen MN and Liston GE (2001) Blue-ice areas in Antarctica derived from NOAA AVHRR satellite data. Journal of Glaciology 47(157), 325-334.

Young NW and Hyland G (2002) Velocity and strain rates derived from InSAR analysis over the Amery Ice Shelf, East Antarctica. Annals of Glaciology 34, 228-234. doi: 10.3189/172756402781817842.

\section{Appendix A: Travel time uncertainty}

The seismic dataset contains a regular non-fixable error in the raw travel time picks. The travel times at individual offsets are in some cases separated by up to $0.8 \mathrm{~ms}$. Figures 5 and 6 show the individual and merged travel time picks for the suture zone site of the upstream sample area, for both the whole offset and an enlarged middle section. The merged travel time profiles show a distinct sawtooth pattern, especially in the enlarged middle part of the profile (Fig. 6, bottom) between 30 and $360 \mathrm{~m}$. Tests using synthetic data show that this pattern can be created by shifting the first arrival travel time profiles of single shot locations by 1-3 m prior to merging them to one continuous travel time profile. This indicates that the recorded location of some shots was incorrect. We account for this shot location misplacement when calculating the model error via sensitivity testing (see also Appendix B).
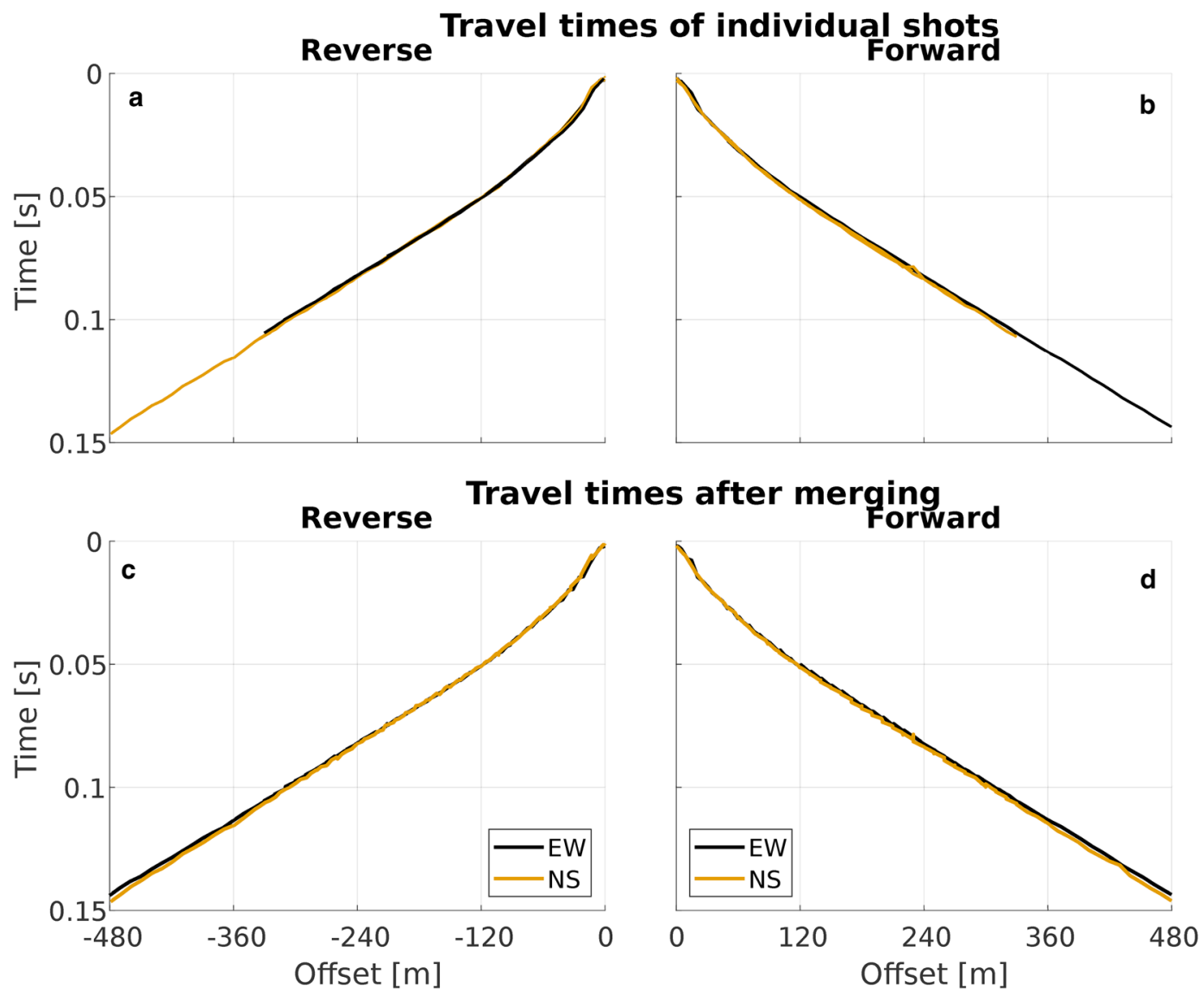

Fig. 5. Picked raw travel times of the whole upstream suture zone shot gather, separated into forward and reverse shots. (a, b) Travel times displayed in shot gathers, with each line representing one shot gather. $(c, d)$ Shot gathers merged into their respective travel time profiles; travel times of the EW shot direction are shown in black, travel times of the NS shot direction are shown in orange (all plots). 


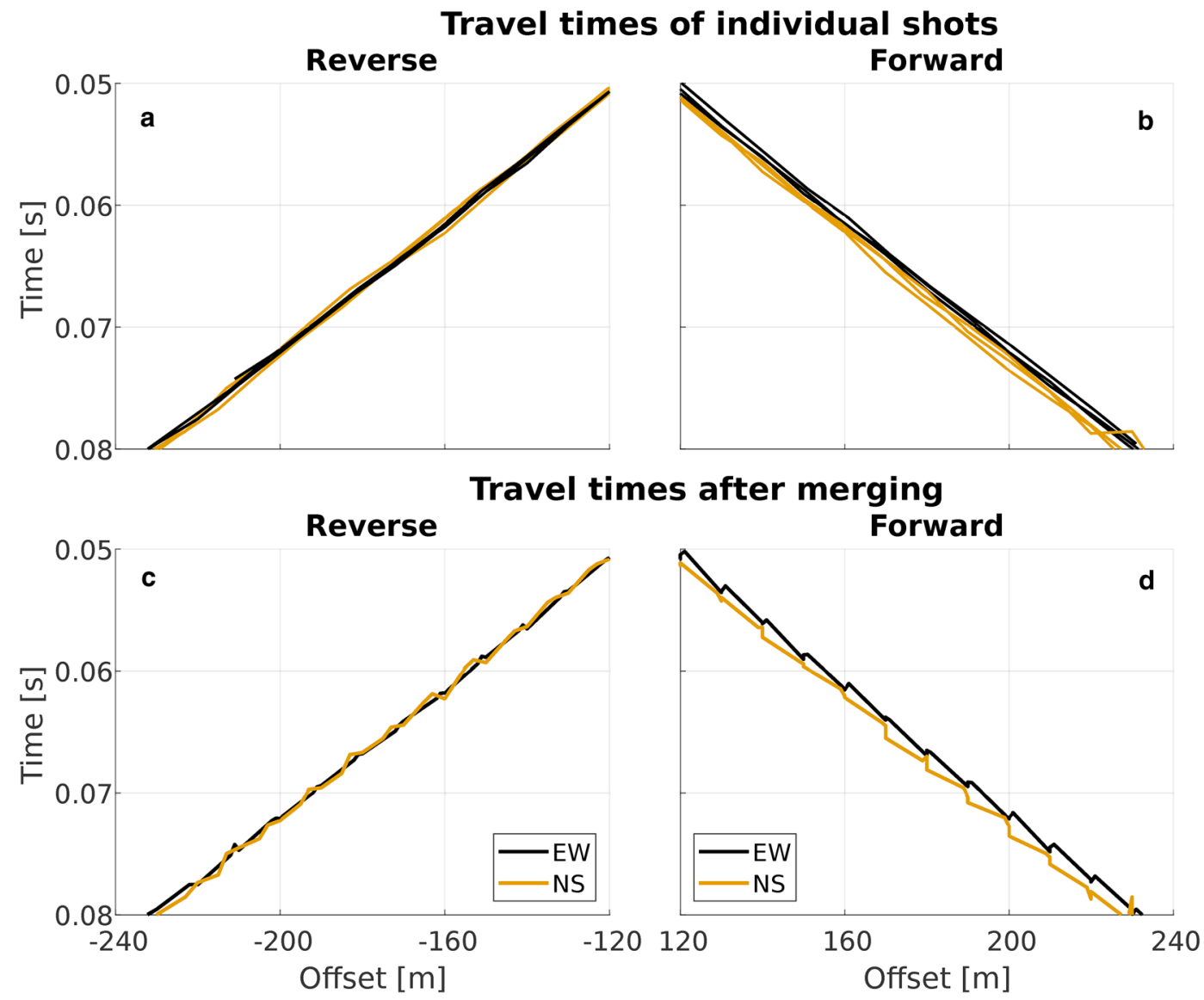

Fig. 6. Picked raw travel times of the upstream suture zone shot gather at offsets $120-240 \mathrm{~m}$, separated into forward and reverse shots. (a, b) Travel times displayed in shot gathers, with each line representing one shot gather. (c, d) Shot gathers merged into their respective travel time profiles; travel times of the EW shot direction are shown in black, travel times of the NS shot direction are shown in orange (all plots).

\section{Appendix B: Sensitivity test and model error}

In this study, the first arrival travel times were picked manually for each shallow seismic refraction profile. At all sites misplacements of shot locations of up to $3 \mathrm{~m}$ led to picking uncertainties of up to $0.45 \mathrm{~ms}$. Signal to noise ratio was generally high and wavelets clearly exposed, so that the cumulative picking uncertainties are an order of magnitude smaller than the shot location misplacements. In agreement with Brisbourne and others (2014) we therefore estimate picking uncertainty to generally be better than $\sim 0.5 \mathrm{~ms}$. The consequential error in seismic velocity and penetration depth are determined by adding and subtracting the picking uncertainty to the raw picked travel times and applying the velocitydepth inversion of WHB to the new travel time profile. The picking uncertainty is applied to the picked seismic travel times in the following ways:

(1) Adding the maximum uncertainty to all data points.

(2) Subtracting the maximum uncertainty from all data points.

(3) Linearly decreasing picking uncertainty, starting at positive maximum and ending at negative maximum.

(4) Linearly increasing picking uncertainty, starting at negative maximum and ending at positive maximum.
(5) Linearly decreasing picking uncertainty at near-offset (offset $\leq 100 \mathrm{~m}$ ), starting at positive maximum and ending at negative maximum.

(6) Linearly increasing picking uncertainty at near-offset (offset $\leq 100 \mathrm{~m}$ ), starting at negative maximum and ending at positive maximum.

(7) Adding $3 \mathrm{~m}$ to one data point of the offset every $10 \mathrm{~m}$ to imitate the shot location misplacement. We limited it to offsets between 30 and $360 \mathrm{~m}$ in accordance with our findings. About $40 \%$ of the data were changed and the travel time was not altered for this test.

(8) Subtracting $3 \mathrm{~m}$ to one data point of the offset every $10 \mathrm{~m}$ to imitate the shot location misplacement. We limited it to offsets between 30 and $360 \mathrm{~m}$ in accordance with our findings. About $40 \%$ of the data were changed and the travel time was not altered for this test.

Next, the difference between the maximum and minimum values of penetration depth and seismic velocity of all nine velocity-depth profiles (including the original profile) was determined for every offset. The result was a single profile for penetration depth and seismic velocity that we used as a measure of the model error (Fig. 7). The model error, especially at large offsets, is considerably larger than what can be found in other studies (Kirchner and Bentley, 1979). This is mainly due to the shot location misplacements, as described in Appendix A (Figs 5 and 6). 


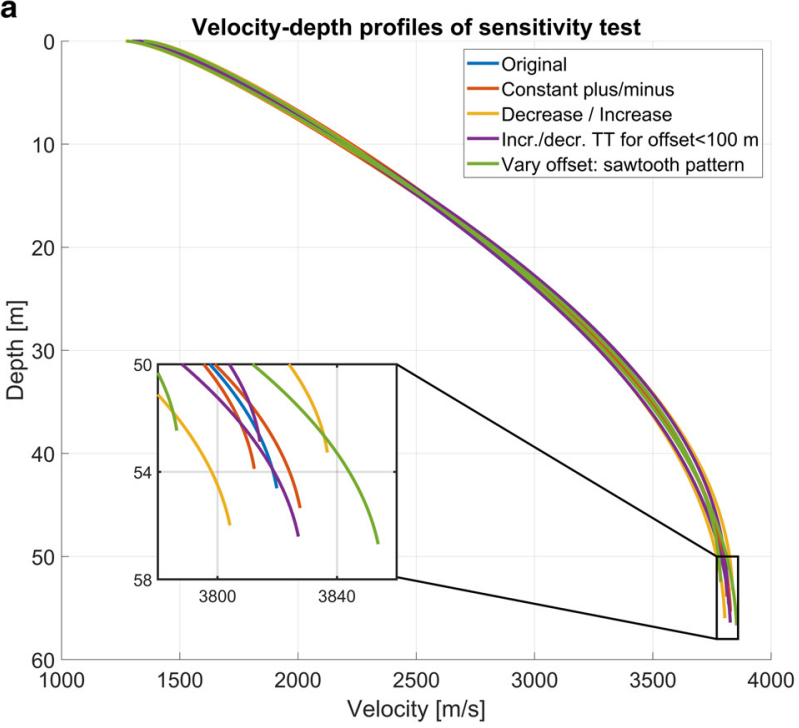

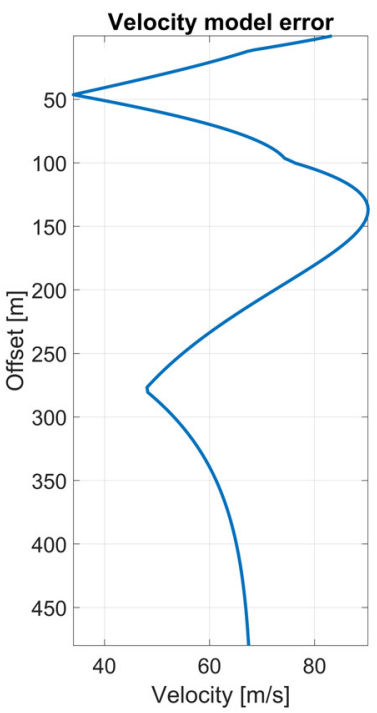

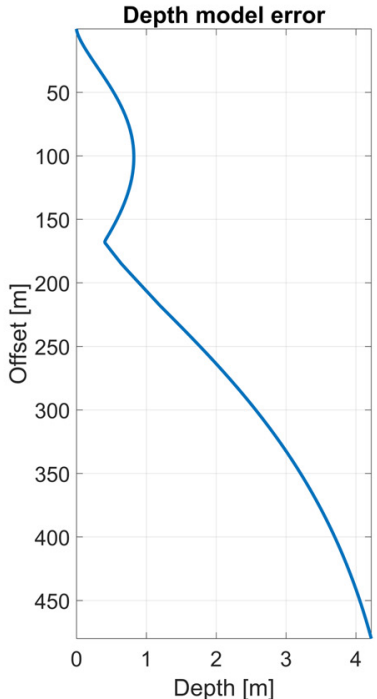

Fig. 7. Error in seismic velocity and penetration depth assuming a $\pm 0.5 \mathrm{~ms}$ picking uncertainty. (a) Velocity-depth profiles after applying the picking uncertainty to the travel times in different ways (see legend). (b) Range of the velocity error versus offset. (c) Range of the depth error against offset. 